\title{
Strength analysis of bamboo and steel reinforced concrete beam
}

\author{
S.K. JAIN, S.P. KURHEKAR AND CHETAN WADEKAR
}

\begin{abstract}
Bamboo possesses excellent strength properties that are as good as other building materials like steel, concrete and timber; therefore bamboo is widely used in the construction industry as reinforced material for reinforcement of concrete, for columns and as propping system for supporting structures in construction industry. The average flexural strength of unreinforced concrete beam (mass concrete) after 28 days curing period was found to be $5.73 \mathrm{MPa}$. The average flexural strength of steel reinforced concrete beam after 28 days curing period was found to be $11.39 \mathrm{MPa}$. The average flexural strength of singly bamboo strip reinforced concrete beam after 28 days curing period was found to be $8.69 \mathrm{MPa}$. The average flexural strength of doubly bamboo strip reinforced concrete beam after 28 days curing period was found to be $12.38 \mathrm{MPa}$. Cracking moment for beam found to be $7.22 \mathrm{kN}-\mathrm{m}$. Flexural strength of bamboo is good and can be used as reinforcement in R.C.C. structure for low cost housing.
\end{abstract}

KEY WORDS : Strength analysis, Bamboo, Steel reinforced concrete bean

How to cite this Article : Jain, S.K., Kurhekar, S.P. and Wadekar, Chetan (2015). Strength analysis of bamboo and steel reinforced concrete beam Engg. \& Tech. in India, 6 (1) : 41-45. 